\title{
A vila de Corumbá e a Guerra Grande: algumas reflexões
}

\author{
The village of Corumbá and the Great War:some thoughts \\ El pueblo de Corumbá y la Gran Guerra: algunas reflexiones
}

Elaine Cancian ${ }^{*}$

\section{Resumo}

No dia 4 de janeiro de 1865, durante a Grande Guerra (1864-1870), a vila de Corumbá, assentada à margem direita do rio Paraguai, na província de Mato Grosso, foi ocupada pelos soldados paraguaios sem resistência alguma. A notícia da aproximação dos invasores causou uma corrida desordenada dos militares responsáveis pela defesa da vila, que, apinhados nas canoas disponíveis, partiram em direção à Cuiabá deixando grande parte da população e o local desguarnecidos. Este artigo apresenta alguns dos principais efeitos enfrentados em Corumbá a partir da deflagração do conflito entre Brasil e Paraguai.

Palavras-chave: Grande Guerra. Ocupação de Corumbá. Consequências.

\section{Albuquerque, um povoado colonial}

No final do século XVIII, o português e capitão general Luís de Albuquerque de Mello Pereira e Cáceres, então governador da capitania de Mato Grosso, ordenou a ocupação estratégica do rio Paraguai, com o objetivo de neutralizar a expansão castelhana em territórios cujos caminhos fluviais eram importantes para as fronteiras meridionais da colônia. Após reconhecimento da região pelos sertanistas João Leme do Prado e Marcelino Rodrigues Camponês, foi ocupada a elevada barranca de pedra calcária à margem direita do rio Paraguai.

Em 21 de setembro de 1778, os responsáveis pela ocupação da região, Leme do Prado e Camponês, junto aos soldados e demais auxiliares da empreitada, procederam ao ato de fundação do povoado denominado Nos-

\footnotetext{
Doutora em História pela Universidade Federal da Grande Dourados - UFGD, Dourados-MS. Professora da Universidade Federal de Mato Grosso do Sul, Campus do Pantanal - UFMS-CPAN.

Recebido em 06/04/2014 - Aprovado em 27/04/2015 http://dx.doi.org/10.5335/hdtv.15n.2.5649
} 
sa Senhora da Conceição de Albuquerque, "em um assento de terra que decorre para o Rio abaixo" (AYALA; SIMON, 1914, p. 325). Uma cruz de madeira de lei cravada no chão simbolizou a tomada de posse do território pela Coroa lusitana.

Nos primeiros tempos de ocupação, existiu às margens do rio Paraguai pequeno povoado formado por algumas famílias, que viviam em habitações simples, construídas com materiais pouco duráveis, como o barro e a palha. Tais edificações mantiveram-se, com certa exclusividade, até a segunda metade do século XIX, quando algumas casas residenciais e comerciais foram sendo construídas com a pedra abundante no local. Enquanto as relações litigiosas entre Portugal e Espanha permaneciam latentes devido às atividades de demarcação territorial na América, os habitantes do povoado de Albuquerque conviveram com a rusticidade.

Raul Silveira de Mello (1964), ao escrever obra sobre a trajetória do tenente-coronel e engenheiro Ricardo Franco de Almeida Serra, mostrou que a população de Albuquerque esteve impedida pelas autoridades portuguesas de edificar moradias permanentes. Conforme Mello, em setembro de 1790, o português José Antônio Pinto de Figueiredo, comandante de Albuquerque, ao ter contato com o capitão da Marinha espanhola e membro da comissão de limites, dom Martin Boneo, observou que

[...] o povoado de Albuquerque tudo produzia bem e, portanto, no sentido de melhorar-lhe as condições de habitabilidade, propôs construir ali casas duráveis, de tijolo e telhas (MELLO, 1964, p. 129).
E ainda:

A isso lhe respondeu o capitão-general que tratasse tão só de conservá-lo nas condições em que estava, até que se realizassem as demarcações, pois poderia acontecer que esses terrenos passassem à Espanha e tudo o que ali fizessem ficaria perdido (MELLO, 1964, p. 129).

Em 1790, a povoação de Albuquerque tinha sessenta casas edificadas em barro e palha, uma capela em adoração a Nossa Senhora do Carmo, com registros de 160 matrimônios, além de dezoito soldados e muitos indígenas. A população plantava cana-de-açúcar, mandioca, melancia, melão e outros alimentos. $\mathrm{O}$ escasso algodão recolhido era usado no tecido produzido para as vestimentas. A alimentação cotidiana consistia de alimentos como: farinha, feijão, melado, rapaduras e toucinho. À época, havia um total de cinquenta cabeças de gado vacum, originárias de sete animais inseridos no local, após longa viagem através dos caminhos fluviais. Os vacuns eram empregados como montaria, para o plantio de roça e para movimentar o engenho. A região era abundante em pedra de cal e barro adequado para a fabricação de telhas e tijolos. No entanto, como referido, predominavam as edificações elevadas com paredes de madeira preenchidas com barro e cobertura de folhas de palmeiras nativas (MELLO, 1964, p. 102-103).

As oscilações políticas refletidas nos tratados de limites assinados entre as coroas portuguesa e espanhola desfavoreceram por longo tempo a constituição de um povoado formado por habitações construídas com materiais mais duráveis, a despeito dos esforços dos administradores portugueses. 
A carta enviada por Ricardo Franco de Almeida Serra ao governador da capitania, Caetano Pinto de Almeida, para informar sobre o incêndio ocorrido na povoação de Albuquerque, nos permite afirmar que, até o ano de 1800, a única edificação coberta de telha era a igreja. $\mathrm{O}$ incêndio de 25 de junho devastou o pequeno povoado. As moradias cobertas de capim e de palha foram rapidamente destruídas e somente a capela resistiu, por possuir cobertura de telha e ter sido elevada em local afastado dos ranchos. Almeida Serra escreveu em sua carta:

Em 25 de junho, pelas oito horas da manhã ardeu em três minutos de tempo toda a Povoação de Albuquerque sem que ficasse uma só casa, nem um esteio, que se não reduzisse a cinzas; escapando unicamente a Capela por ser coberta de telha e ilhada havendo apenas tempo para se salvar o pouco trem de Sua Majestade que estava no armazém, o que não sucedeu com o milho, pois o fogo o devorou em uma casa em que guardava, assim como o mais milho mantimentos do monte. ${ }^{1}$

No ano de 1786, o chefe da comissão de engenheiros, Ricardo Franco de Almeida Serra, percorreu o povoado de Albuquerque. De acordo com suas impressões, o local apresentava-se semelhante a um forte comandado por normas militares e disciplina rígida. Os habitantes trabalhavam muito, alimentavam-se mal e usavam vestes grosseiras. Seus escritos mostram que a fortaleza tinha a figura de um grande pátio retangular, fechado com casas em roda e um portão na frente, constando de 75 passos de comprido e cinquenta de largura. A população constava de duzentas pessoas, que plantavam milho e feijão, produtos superabundantes para o consumo anual. Os habitantes locais cultivavam também em abundância o algodão, o qual, depois de transformado em tecido, era comercializado em Cuiabá, por meio de troca por outros produtos necessários. Além do cultivo de roças, praticavam-se a pesca e a caça (SERRA, 1786, p. 76).

\section{Impressões de viagem}

Em 14 de dezembro de 1826, ao passar por Albuquerque, o viajante francês Hércules Florence registrou a precariedade das moradias da povoação. Ainda nesse período, havia no povoado "quatro filas de casas em torno de uma praça, uma pequena capela que intitulavam de igreja, e uma casa para os militares". Registrou que a população teria uns cinco brancos e os restantes eram crioulos, caburés, mestiços e índios (FLORENCE, 1977, p. 103).

O viajante francês Francis Castelnau (1987), chefe da expedição francesa enviada ao Brasil, esteve no vilarejo de Corumbá, em 7 de fevereiro de 1845. As impressões de Castelnau sugerem que o local era uma espécie de povoado, pequeno e desfavorecido, pois grande parte dos habitantes se deslocaram para Albuquerque, que, até 1826, era uma fazenda real. Conforme o viajante, a população era formada por cem pessoas, entre brancos, indígenas e negros, "descendentes de indivíduos deportados para esse lugar, que foi outrora presídio" (1987, p. 238). Relativo às edificações, registrou:

[...] uma igrejinha em ruínas, [...] uma fileira de dez casebres unidos uns aos outros de modo a formar uma casa única e tendo como fecho das portas e janelas um simples couro de boi (1987, p. 238). 
Chamou sua atenção a abundância de pedra calcária existente na localidade, da qual os habitantes extraíam a cal "exportada tanto rio acima como rio abaixo" (1987, p. 239).

As moradias de pau a pique, com paredes preenchidas de barro e cobertas de palha, permaneceram, exclusivamente, até 1858, quando o comerciante português Manoel Cavassa, estabelecido na então vila de Corumbá, levantou a primeira construção em alvenaria. Conforme os registros deixados por Cavassa em documento intitulado Memorandum, no ano de sua chegada, 1857, existia na vila quatro ranchos de palha e nenhuma construção de material, sendo ele o primeiro a edificar casa de alvenaria para depositar as mercadorias e, posteriormente, outras cinco casas. Assim expôs:

Logo que foi franqueada a navegação do rio Paraguay para Matto-Grosso, desejando conhecer esta parte do Brasil, prontifiquei-me em fins de 1857, e vim para esta cidade [Corumbá], que era então um lugar ermo, onde somente havia quatro ranchos de palha e nem uma só casa, pelo que vi-me obrigado a fazer do navio armazém, vendendo ahi as mercadorias, que tinha trazido, aos habitantes d'este lugar e às embarcações que vinhão da Capital, de Villa Maria e de Miranda.

\section{Manuel Cassava continua:}

Vendo que d'este modo prolongar-se-ia inconvenientemente a estada do navio, que já aqui estava havia 10 meses, julguei conveniente mandar construir uma casa (que foi a primeira aqui edificada), para deposito do resto do carregamento, [...]. É verdade que, aqui tendo-me domiciliado, ganhei muito dinheiro [...], pois pelos balanços de 1864 as minhas casas representavão um capital de mil quatrocentos e tantos contos de reis (CORRÊA; CORRÊA, 1997, p. 20-21).

\section{Tratado de Amizade, Comércio e Navegação}

É importante ressaltar que a chegada de Cavassa à região, por via fluvial, portando mercadorias para serem comercializadas, e sua fixação no local, enquanto proprietário de estabelecimento comercial, só foram possíveis devido ao estabelecimento do Tratado de Amizade, Comércio e Navegação, em 6 de abril de 1856, entre Brasil e Paraguai, que possibilitou a abertura do rio Paraguai à navegação. Conforme a historiadora sul-mato-grossense Maria do Carmo Brazil, a convenção firmada entre os administradores brasileiros e os paraguaios:

[...] embora não tenha solucionado a questão de limites entre as duas nações, permitiu o comércio regular entre Montevidéu e Cuiabá [...]. Corumbá, Cuiabá e Cáceres experimentaram um dinâmico fluxo econômico devido ao acesso do grande rio ao comércio internacional (2014, p. 165).

O porto geral de Corumbá tornou-se local de intenso movimento de indivíduos envolvidos com a comercialização de mercadorias, com as atividades alfandegárias e demais serviços. Ele tornou-se, igualmente, grande via de acesso às demais localidades da província de Mato Grosso. A movimentação era avolumada pelos viajantes estrangeiros, pois Corumbá era a primeira aglomeração mato-grossense onde os estrangeiros paravam, antes de seguir viagem para seus destinos finais. ${ }^{2}$ No porto, atracavam navios nacionais e estrangeiros, carregados de mercadorias para o comércio atacadista, que distribuía as mercadorias pela província. Corumbá transformou-se em praça comercial, 
constituída por comerciantes nacionais e estrangeiros, acesso e porta de entrada para a província mato-grossense.

Em estudo de fôlego que elegeu o rio Paraguai como objeto de investigação, Maria do Carmo Brazil registrou a circulação intensa de vapores na região. Os vapores denominados Alfa, Corumbá, Cuiabá, Cuiabazinho e Jauru circulavam pelo rio Paraguai, ligando Corumbá, Cuiabá e Cáceres com o exterior, através do rio da Prata. Brazil mostra a intensificação do comércio fluvial a partir de 1858, quando ocorreu a organização de uma companhia de navegação, para facilitar o deslocamento de pessoas e mercadorias entre Montevidéu e Cuiabá. Denominada Companhia de Navegação a Vapor, agregava os vapores Conselheiro Paranhos, Cuiabá Marquês de Olinda e Visconde de Ipanema, empregados nas viagens regulares (BRAZIL, 2014, p. 218-219).

A dinâmica comercial estabelecida em Corumbá, a partir do Tratado de 1856, ensejou gradativamente a modificação da paisagem local. O espaço urbano reordenou-se, com a abertura de espaços de utilidade pública e a elevação de construções privadas em alvenaria. Em 1858, o presidente da província de Mato Grosso, Joaquim Raymundo Delamare, "mandou delinear-lhe as ruas, praças e demarcar lotes, para as construções dos edifícios públicos" (SOUZA, [s.d.], p. 113-114). O projeto de urbanização elaborado por Delamare traçou ruas e quarteirões da aglomeração em forma de tabuleiro de xadrez, como habitual. No seu governo, foi criada a Mesa de Rendas e a Alfândega, com o objetivo de arrecadar os impostos advindos do comércio.
O edifício da Alfândega foi construído em 1861, em espaço até então desprezado localmente, pois se tratava de terreno baixo, localizado em área bem próxima ao rio $\mathrm{Pa}$ raguai, separado naturalmente da parte alta por elevadas muralhas de pedras, onde foi fundado o primitivo povoado de Albuquerque. $\mathrm{O}$ acesso entre a parte alta e a baixa, até os dias de hoje, é realizado via ladeiras. O fato é que o intenso deslocamento de pessoas e mercadorias e as paradas obrigatórias dos vapores promoveram a ocupação gradativa da margem do rio Paraguai, com a elevação de construções públicas e privadas. O conhecido Porto de Corumbá, na cidade baixa, foi o local escolhido pelos comerciantes para edificação de casas comerciais de importação e exportação de mercadorias. Muitas dessas construções se conservam até hoje.

No ano de 1861, a população local era composta por 1.315 habitantes. Na época, havia 44 trabalhadores escravizados em posse de algumas famílias e 84 estrangeiros. Em pau a pique, havia 36 casas construídas e 29 em fase de construção, havia ainda 109 ranchos de palha (FONSECA, 1880, p. 289). Até 1864, o espaço urbano de Corumbá apresentava ainda muitas moradias simples, apesar da gradativa elevação de edificações em pedra e cal.

\section{Vila de Corumbá}

Em 10 de julho de 1862, uma resolução decretada pela Assembleia Legislativa Provincial, sancionada pelo presidente da província de Mato Grosso, Herculano Ferreira Penna, e publicada na Secretaria do governo, elevou o povoado de Albuquerque à ca- 
tegoria de vila com a denominação Villa de Corumbá. ${ }^{3}$

Naquele ano, o viajante português Joaquim Ferreira Moutinho esteve em Corumbá, e suas impressões sobre o local ficaram registradas na obra Noticia sobre a província de Matto Grosso seguida d'um roteiro da viagem de sua capital a São Paulo, que foi publicada em 1869. Conforme suas memórias, havia na vila oitenta casas, algumas com cobertura de telha e outras de zinco, todas "construídas entre dois jardins, um de cada lado, e estes, fazendo frente para as ruas, [...] fechados por gradis" (MOUTINHO, 1869, p. 245). Também constatou uma quantidade de 140 ranchos com cobertura feita com folhas da Carandá, espécie de palmeira originária da região. O espaço urbano contava também com:

[...] uma pequena capela; e uma igreja em construção, [...] um quartel regular, uma enfermaria, um barracão que servia de alfândega, armazéns de marinha e de artigos bélicos, um cemitério decente, olarias, oficinas, etc. (MOUTINHO, 1869, p. 245).

Sobre a população, afirmou ser de 1.400 brasileiros e cem estrangeiros, totalizando 1.500 indivíduos.

Interessante observar que Moutinho caracterizou a vila como a mais animada e movimentada da província de Mato Grosso. Conforme o viajante, havia localmente cinco casas de jogos de bilhar frequentadas pelas pessoas após o trabalho cotidiano, e constantes bailes regados aos doces de procedência estrangeira, sobretudo trazidos de Montevidéu e Buenos Aires. O porto recebia continuamente diferentes embarcações carregadas de produtos provindos de Cuia- bá, capital da província, do Rio de Janeiro, de Montevidéu e de Buenos Aires, assim como estrangeiros que "davam aquele ponto um aspecto alegre, e muita atividade em toda sorte de negócios, que se faziam todo o dia em larga escala" (MOUTINHO, 1869, p. 244).

João Severiano da Fonseca (1880, p. 298), membro da comissão encarregada de demarcar os limites entre a província de Mato Grosso e a Bolívia, na obra Viagem ao redor do Brasil 1875-1878, registrou a existência na vila, em 1862, de 1.281 pessoas, desse total, 1.126 eram brasileiros, 111 estrangeiros e 34 cativos. A despeito das diferenças de cálculo apresentadas pelos viajantes para o mesmo ano, é preciso considerar a fragilidade das estatísticas, do século XIX, tanto as realizadas por privados como as produzidas pelo governo da província, que contava com a boa vontade dos representantes locais no envio das informações solicitadas. Todavia, é importante observar, além dos números, a quantidade de estrangeiros de várias nacionalidades vivendo em Corumbá - alemães, argentinos, bolivianos, franceses, italianos, portugueses, etc. -, estabelecidos na região em função do comércio via fluvial.

Como consequência da instalação de comércio de importação e exportação de mercadorias, o antigo e pequeno povoado de Albuquerque transformou-se em importante aglomeração portuária regional, finalmente denominada de Corumbá. Todavia, a guerra envolvendo o Brasil e o Paraguai, entre os anos 1864 e 1870, com a invasão do sul do Mato Grosso, rompeu fortemente as relações comerciais estabelecidas até o momento da deflagração do conflito. 


\section{A Guerra Grande e seus efeitos}

No dia 4 de janeiro de 1865, as tropas paraguaias comandadas por Vicente Barrios desembarcaram em Corumbá e encontraram a vila desguarnecida. $\mathrm{O}$ comandante das armas, Carlos Augusto de Oliveira, responsável pela guarnição local, ao obter notícias, no dia anterior, da aproximação dos paraguaios, e sabendo da entrega do forte de Coimbra, reuniu aproximadamente quatrocentos soldados a bordo do vapor Anhambai e seguiu para a capital Cuiabá, junto a outras embarcações. A retirada da tropa brasileira espalhou o pânico entre os moradores, que procuraram "refúgio nas matas sem destino prefixado e sem rumo, num estado de alma próximo à demência" (ALMEIDA, 1967, p. 17).

A vila de Corumbá permaneceu ocupada pelos paraguaios até 13 de junho de 1867. Durante esse período, grandes danos foram causados à população de Corumbá. Os paraguaios praticaram o saque das moradias e casas comerciais, apoderando-se de objetos de valor e mercadorias. As mulheres casadas eram desrespeitadas pelos soldados a bordo do navio de Vicente Barrios, e os homens eram levados até Assunção. Mulheres, crianças e pessoas inválidas permaneceram na vila em poder dos invasores, obrigados ao trabalho forçado (ALMEIDA, 1967, p. 17).

Conforme o relatório do vice-presidente da província de Mato Grosso, o tenente-coronel Albano de Souza Ozorio, houve tentativa por parte da população de Corumbá de se furtar dos desmandos das tropas paraguaias, refugiando-se no território boliviano. A partir do mês de fevereiro de 1865, "alguns estrangeiros, a quem associou-se um brasileiro, guiados por um escravo do Barão de Villa Maria", deram início à abertura de um caminho entre Corumbá e o povoado boliviano mais acessível. A dura empreitada foi executada ao final de quatro meses. Assim, após "grandes trabalhos e privações, chegaram ao povo boliviano do S. Coração, distante de Corumbá 25 a 30 léguas, trajeto que, dizem, faz-se atualmente em 4 dias" ${ }^{4}$

Durante a guerra, grande parte das habitações dos moradores da vila foi arrasada. As casas não destruídas ficaram totalmente inservíveis. Das 171 casas de barro e palha e dos 109 ranchos cobertos de palha, restaram apenas vinte. Foram abatidas as edificações de alvenaria do comerciante Manoel Cavassa. João Severiano da Fonseca registrou o quadro desolador de Corumbá.

A villa [...] não era mais do que um acampamento incendiado e devastado; poucos brasileiros ai existiam entre mulheres e crianças; os homens e algumas famílias que não foram mortas ai mesmo, Barrios fizera-os partir para Assumpção. Em pouco à esses destroços acresceu uma nova e terrível calamidade, a varíola, que, propagando-se por toda a província, devorou-lhe mais de um decimo da população (FONSECA, 1880, p. 294).

As roças das propriedades rurais próximas também foram arruinadas, e os animais vacuns existentes serviram de alimentação aos soldados paraguaios. A exemplo, citamos a fazenda Piraputangas, invadida e saqueada pelos paraguaios quando da Guerra Grande. Ela era de propriedade de Joaquim José Gomes da Silva, conhecido como barão de Vila Maria, pela concessão daquele título pelo Governo Imperial, em 21 de junho de 
1862. A Piraputangas localizava-se próxima à Albuquerque e Corumbá e mantinha abundante produção de alimentos e criação de gado vacum, cuidados por trabalhadores escravizados e livres (PROENÇA, 1992). Além da casa de morada do barão, havia cercados de animais, currais, enfermaria, galpões de palha e quartos construídos, separados para acolherem os viajantes.

O engenho de moer cana e fabricar o açúcar e a aguardente e os galpões de funcionamento das oficinas de carpintaria, ferragens e monjolo movido por água completavam a paisagem da Piraputangas (CANCIAN; BRAZIL, 2008, p. 106).

Ao visitar a fazenda do barão, em 1862, Joaquim Ferreira Moutinho ressaltou em suas memórias que o engenho Piraputangas era digno de atenção por se apresentar, antes da guerra, como o melhor estabelecimento da região. $\mathrm{O}$ viajante registrou sobre a propriedade:

Dai saia grande parte do sustento para Corumbá; acrescendo que a maior parte do gado que ali se consumia era tirado das fazendas do mesmo barão, próximas do Engenho, onde residia em riquíssima casa, perto da fábrica movida por água, entre ricos pomares, e belas e abundantes plantações, disposto tudo com muito gosto, regularidade, e até com luxo (MOUTINHO, 1869, p. 245-246).

O barão de Vila Maria teve, além da Piraputangas, outras propriedades igualmente invadidas pelos paraguaios, e grande parte dos seus rebanhos vacuns foi subtraída. Terminado o conflito em 1870, restaram as posses arruinadas e algumas apólices a serem pagas pelo governo paraguaio. Devido ao fato de o Paraguai não ter sido obrigado a cumprir o prazo limite para saldar as dívidas da guerra, o barão permaneceu com situação financeira prejudicada e teve que recorrer a empréstimos em dinheiro. A guerra do $\mathrm{Pa}-$ raguai foi o fator desencadeador da ruína do barão de Vila Maria, consumada pela má fé de um procurador.

Augusto César Proença, na obra Pantanal, gente, tradição e história, registrou a respeito:

Devido à pouca quantidade de gado que lhe sobrou [ao barão de Vila Maria] não conseguiu saldar as dívidas contraídas, entregou tudo por uma bagatela, e dizem que ainda foi pressionado pelos negócios fraudulentos de um procurador que, aproveitando uma das suas idas ao Rio de Janeiro, falsificou-lhe a assinatura, tornando-se dono de muitas das propriedades, matando o juiz e incendiando o cartório como queima de arquivo (1992, p. 75).

João Severiano da Fonseca registrou que, antes de seu rebanho ser levado e de ser devastada pelos paraguaios, Piraputangas foi "uma das primeiras da província em riquezas de gados e prosperidade na safra do açúcar, farinha, milho, arroz e feijão, com que abastecia a cidade" (FONSECA, 1880, p. 303). Terminado o conflito, restaram ao barão de Vila Maria a propriedade arruinada, poucas cabeças de gado e vultosa dívida, que arruinou as finanças da família por longo tempo. ${ }^{5}$

Além de causar a desorganização das fazendas, o empobrecimento de fazendeiros e comerciantes locais, a Guerra Grande comprometeu o abastecimento de toda a província de Mato Grosso. O comércio de importação de gêneros de primeira necessidade e outras mercadorias e de exportação de matérias-primas da região mato-grossense, por 
meio do rio Paraguai, desenvolvido após o Tratado de Amizade, Comércio e Navegação (1856), como já referido, foi interrompido. O porto de Corumbá, até então, beneficiado com as relações comerciais praticadas devido à sua posição privilegiada de entreposto de abastecimento do território mato-grossense, ao ter suas atividades suspensas, levou a vila à desolação, sobretudo porque esteve sob o domínio invasor até 1865 .

A expulsão dos paraguaios da vila de Corumbá, em 13 de junho de 1867, permitiu à população iniciar a reconstrução das moradias e a retomada das atividades cotidianas. O comércio local foi sendo restabelecido gradativamente. Em 1869, para incentivar as atividades comerciais na região, o governo imperial isentou os comerciantes do pagamento dos tributos sobre os produtos importados e exportados por intermédio do porto local. Os incentivos comerciais tornaram-se em um chamariz ao comércio.

\section{Fortificarpara defender}

Terminada a Guerra Grande, em 1870, a defesa da província de Mato Grosso foi pauta de discussão das autoridades mato-grossenses. Como consequência da necessidade de resguardar as áreas mais vulneráveis, Corumbá tornou-se um espaço extremamente fortificado. A reorganização defensiva da região foi planejada por uma comissão de engenheiros militares, que projetou um conjunto de cinco fortins, quatro "dispostos na forma de um quadrilátero" e um "isolado das trincheiras" (GALLO, 1983 , p. 26-27). Assim, a partir de 1871 , a paisagem urbana local passou a contar com as seguintes fortificações, elevadas no perímetro urbano local: Conde D'Eu, Duque de Caxias, Limoeiro (depois São Francisco); Major Gama e Santo Antônio. Distante um quilômetro da cidade, também edificado na mesma época e presente até os dias de hoje, consta o antigo forte Pólvora, atualmente conhecido por Junqueira.

Os fortins São Francisco e Junqueira foram edificados no governo do tenente coronel Francisco José Cardoso. Depois de visitar Corumbá, Cardoso observou a necessidade da execução de obras que promovessem a defesa da vila e do rio Paraguai. Em relatório apresentado à Assembleia Legislativa do Mato Grosso, em 1871, comunicou a determinação da implantação de construção necessária para resguardar Corumbá. Sobre a questão, registrou:

Na minha passagem por Corumbá vi que grande parte da artilharia lá existente estava em mau estado de conservação e que a permanecer assim podia inteiramente deteriorar-se. Vi também que era necessário fazer ali uma fortificação mais ou menos regular, de modo a dar uma aparência militar àquele ponto, e por isso, apenas cheguei à Capital, determinei o preparo de uma elevação que não só domina a povoação, como também o rio para nela assentar-se a artilharia que está junto à barranca. $\mathrm{O}$ indicado lugar denomina-se Castello. A obra que é militar será feita pelas praças do $2^{\circ}$ Batalhão de artilharia a pé, estacionado em Corumbá, as quais assim terão ocupação mais constante, deixando a indolência que é o primeiro degrau para toda a sorte de vícios. ${ }^{6}$

Conforme levantamento realizado em 1983, para a Secretaria de Desenvolvimento Social do município de Corumbá, pelo arquivista José Roberto Gallo, o forte Conde 
D'Eu abrangia "dois lotes de terreno na rua Ladário [72,80 m], dois na América [63,60 m] e um lote na junção das duas ruas", e suas obras, inconclusas, não deixaram vestígios materiais. O forte Major Gama, localizado na área sul da cidade, à época da pesquisa, resumia-se a poucas sobras construtivas. $\mathrm{O}$ forte Duque de Caxias, com planta datada de 1889, construído de forma irregular, tinha muralhas frágeis e abrigava nove canhoneiras e duas plataformas para canhões. Nos anos 1980, nada restava de suas fundações, cobertas por aterro (GALLO, 1983, p. 26).

O forte São Francisco, inaugurado em 25 de maio de 1871, apresentava traçado de um octógono com " 2 retângulos, em que o lado menor de um se achava ligado ao maior de outro", e rampa de acesso (GALLO, 1983, p. 26). Localizado entre os fortins de Santo Antônio e Duque de Caxias, foi destruído com o passar do tempo. O forte Santo Antônio, desenhado de forma irregular em 1889, também possuiu canhoneiras e plataformas para canhões. Finalmente, o forte Junqueira, projetado, em 1889, como "um polígono de 8 lados, em que dois ângulos são reentrantes, assemelhando-se, a um quadrado ligado ao lado maior de um retângulo", com " 8 canhoeiras sendo duas em cada face do quadrado e uma em cada extremo do retângulo", e "artilhamento de 12 peças" (GALLO, 1983, p. 26). O forte Junqueira, conservado até os dias atuais pelo $17^{\circ}$ Batalhão de Fronteira, mantém doze canhões Krupp raiados, fabricados entre os anos de 1872 a 1884, em grande parte fabricados no ano de 1874 .

Restabelecida a defesa da cidade por meio de novas fortificações e retomado o comércio fluvial, novos comerciantes foram se estabelecendo em Corumbá, construindo casas comerciais, a partir de 1872. No mesmo ano, instalou-se a alfândega para armazenar produtos e arrecadar impostos de importação e exportação, seguida pela Câmara Municipal, em 17 de agosto de 1872. Nesse período de reorganização, também foram reconstruídas moradias. Em 1873, já havia 455 casas elevadas em pedra e cal, cobertas de telhas, e 25 moradias em construção. Outras sessenta moradias edificadas tinham cobertura de zinco.

Em 1877, a vila tinha diversas ruas amplas, chamadas Alencastro, Augusta, Bela, Bela Vista, Cadeia, Câmara, Delamare, Major Gama, Ocidental, Oriental, Palácio, Primeiro de Abril, Santa Teresa, São Gabriel, São Pedro, Sete de Setembro, Vinte e Três de Julho, e três praças denominadas Carmo, Santa Teresa e São Pedro. As casas comerciais e muitas moradias concentravam-se na Rua Delamare. A localidade contava com a cadeia, a câmara municipal, a casa do comando do $2^{\circ}$ Batalhão de Artilharia, a capela de Nossa Senhora da Candelária, o cemitério público e depósito de artigos bélicos, todas as construções em bom estado. Em péssimas condições construtivas havia o hospital militar, os quartéis e uma pequena construção que servia de capitania dos portos. Em ano anterior, 1876, a população local foi calculada entre 5 e 6 mil habitantes (FONSECA, 1880, p. 295296). No mês de novembro de 1878 , a vila de Corumbá foi elevada à categoria de cidade. Nessa época o espaço urbano local possuía 540 casas, 455 com cobertura de telha e 51 de zinco. Havia 34 moradias em construção, 25 de telha e nove de zinco (FONSECA, 1880, p. 297). 


\section{0 espetáculo da miséria nas ruas}

A Guerra Grande causou efeitos negativos imediatos para Corumbá. A presença dos paraguaios causou violência, assassinatos, despojo de bens, interrupção do comércio, fuga de civis e militares, propagação de doenças, destruição de edificações, desordem das fazendas. Campo e cidade foram devastados. Todavia, anos depois, quando a vila já havia sido reerguida, a população local ainda convivia com outras consequências da guerra.

No ano de 1876, quando as forças brasileiras de ocupação retiraram-se do Paraguai, cerca de 3.000 a 4.000 paraguaios as acompanharam até a vila de Corumbá. Conforme registrado por João Severiano da Fonseca, as embarcações "Visconde de Inhauma, o Madeira e outros grandes transportes, conduziam em cada viagem, com a tropa perto ou mais de 1.500 paraguaios" (FONSECA, 1880, p. 299).

Em dissertação de mestrado, intitulada "A inserção de estrangeiros nas sociedades fronteiriças: o caso dos paraguaios em Corumbá, MS", de 2009, Kiase Sebastiana Moraes Siqueira explicou que as mulheres e os homens paraguaios que imigraram para Corumbá enfrentaram várias dificuldades, sobretudo o preconceito das autoridades e demais habitantes locais. Conforme a autora, tais imigrantes executavam diferentes tipos de trabalhos, tanto na cidade quanto nas propriedades rurais, sempre de modo coercivo. Entretanto, os não integrados ao trabalho "viviam em condições precárias, dependendo muitas vezes da caridade de outros, eram, pelas circunstâncias, vítimas da fome, da completa miséria" (SIQUEIRA, 2009, p. 42).
Devido ao fato da inexistência de emprego suficiente para absorver como mão de obra todos os paraguaios que aportavam na vila de Corumbá, ocorreu a formação de uma população de estrangeiros, vivendo seus cotidianos nos espaços públicos. $\mathrm{Na}$ condição de mendigos, muitas vezes doentes e maltrapilhos, os paraguaios permaneciam nas ruas implorando a oferta de esmolas.

\section{Porto franqueado}

A partir de 1870, encerrado o conflito com o Paraguai, iniciativas do governo imperial ajudaram na reconstrução de Corumbá. Com o objetivo de auxiliar o desenvolvimento local, uma vez que a guerra havia devastado a localidade e causado grandes danos à população, o porto foi franqueado à importação e à exportação de produtos de origens diversas. A retomada das atividades comerciais propiciou o crescimento de Corumbá, por continuar a ser local de parada obrigatória para embarque e desembarque de mercadorias, chegadas através do rio Paraguai.

No porto geral da cidade, havia intenso movimento de indivíduos envolvidos com o comércio e nas atividades da alfândega. Cativos originários e pobres livres realizavam o serviço específico do local: amarravam embarcações nos atracadores, carregavam e descarregavam as cargas dos navios, deslocavam os produtos até os armazéns, executavam as tarefas mais pesadas. Navios nacionais e estrangeiros aportavam nos atracadouros carregados de mercadorias, que eram distribuídas pelo comércio atacadista em toda a província. 
Diversos comerciantes instalaram suas empresas em Corumbá, com o objetivo de comprar e vender mercadorias variadas, atendendo a demanda local e a da província de Mato Grosso. No porto de Corumbá, atracavam navios com produtos de Portugal, Alemanha, Inglaterra, França, Áustria, Itália, Bélgica, e despachados pelo Rio de Janeiro. Esses produtos consistiam em armas, chapas de aço, chapéus, charutos, ferragens, goma arábica, louças, manteiga, maquinarias, móveis, roupas, utensílios de ferro, vinhos, etc. Algumas mercadorias produzidas na região eram despachadas pela alfândega de Corumbá para Argentina, Uruguai e países europeus. Os produtos e manufaturados agrícolas, como o açúcar e a rapadura, o gado vacum, cavalar e seus derivados (couros, ossos, sebo), os produtos do extrativismo vegental, borracha, cal, erva-mate, manganês e poaia, as peles de onça, as penas de garças, etc., eram todos embarcados e transportados via fluvial para os países importadores (Alfândega de Corumbá, 1988, p. 11). ${ }^{7}$

A movimentação intensa do comércio de importação e exportação ocasionou a edificação de importantes casas comerciais em Corumbá. Assim, no final do século XIX, às margens do rio Paraguai e encostadas à alta muralha de pedra, foram elevadas imponentes construções para servirem de armazém e escritório. Edificadas com grossas paredes geminadas em pedra e cal e fachada alinhada à via pública, são representações de uma época de grande circulação de mercadorias, capital e indivíduos estrangeiros, permitida para a reconstrução local após a Guerra Grande. Atualmente, a maioria foi transformada para cumprir novas funções, e servem de registro histórico daquela intensa atividade comercial e humana.

\section{Abstract}

On January $4^{\text {th }}, 1865$, during the Great War, 1864-1870, village of Corumbá, founded on the right bank of the Paraguay River in the province of Mato Grosso, was occupied by Paraguayan soldiers without any resistance. The news from the invader's approaching caused a disorderly race of the military responsible for the village's defense, crowded in canoes available, they departed towards Cuiabá leaving the major part of the population and the place unguarded. The article presents some of the main effects faced in Corumbá from the outbreak of the conflict between Brazil and Paraguay.

Keywords: Great War. Occupation of Corumbá. Consequences.

\section{Resumen}

El 4 de enero de 1865, durante la Gran Guerra, 1864-1870, la ciudad de Corumbá, sentado en la orilla derecha del río Paraguay en la provincia de Mato Grosso, fue ocupada por soldados paraguayos sin resistencia. La noticia de que los invasores se acercaban causó una carrera desordenada de los militares responsables para la defensa del pueblo, y juntos en canoas disponibles, partieron hacia Cuiabá dejando gran parte de la población y el lugar sin vigilancia. El artículo presenta algunos de los principales efectos que se enfrentan en Corumbá desde 
el estallido del conflicto entre Brasil y Paraguay.

Palabras clave: Gran Guerra. Ocupación de Corumbá. Consecuencias.

\section{Notas}

1 Ofício de Ricardo Franco de Almeida Serra a Caetano Pinto de Miranda Montenegro. Presídio de Coimbra, 30 de junho de 1800. ACBM/IPDAC. Pasta: 67 . Documento $\mathrm{n}^{\mathrm{o}} 1.887$.

2 Relatório do Presidente da Câmara Municipal de Corumbá, em 24 de setembro de 1884. Arquivo da Câmara de Corumbá-MS.

3 Ofício $n^{\circ}$ 6. Palácio do Governo de Mato Grosso em Cuiabá, 11 de julho de 1862. Arquivo da Câmara Municipal de Corumbá.

4 Relatório do vice-presidente da província de MattoGrosso. Ill $^{\circ}$ e Exm ${ }^{\circ}$ Senr. Tenente-coronel Albano de Souza Ozorio, Barão de Melgaço, em 8 de maio de 1866. Cuiabá: Typ. de Souza Neves, 1866. p. 5.

5 Inventário dos bens do Barão de Villa Maria, 1876. Arquivo e Memorial do Tribunal de Justiça de Campo Grande-MS.

6 Relatório apresentado à Assembléa Legislativa do Mato Grosso pelo $\mathrm{Exm}^{\circ} \mathrm{Sr}^{\circ}$ Tenente-coronel Francisco José Cardoso Junior, em 20 de agosto de 1871. Cuiabá: Typ. de Souza Neves \& Compa . p. 18.

7 Alfândega de Corumbá. Fundação Universidade de Mato Grosso. Coordenação de Cultura. Núcleo de Documentação e Informação Histórica Regional. Brasília: Ministério da Fazenda; Divisão de Documentação, 1988. p. 11.

\section{Referências}

ALMEIDA, Valerio de. $1^{\circ}$ centenário da retomada da vila de Corumbá. Corumbá: [s. n.], 1967.

AYALA, S. Cardoso; SIMON, F. Álbum gráphico de Matto Grosso. Corumbá: Hamburgo, 1914.

BRAZIL, Maria do Carmo. Rio Paraguai. O “Mar interno" Brasileiro. Campo Grande: UFMS, 2014.

CANCIAN, E.; BRASIL, M. C. O barão de vila Maria. Poder, história agrária e memória em Mato Grosso. In: BORGES, Fernando T. de M.; PERARO, Maria A.; COSTA, Viviane G. da S.
(Org.). Trajetórias de vidas na história. Cuiabá: UFMT, 2008.

CORRÊA, Valmir Batista; CORRÊA, Lúcia Salsa. Memorandum de Manoel Cavassa. Campo Grande: UFMS, 1997.

CASTELNAU, Francis. Expedições às regiões centrais da América do Sul. Tradução deOlivério M. de Oliveira Pinto. São Paulo: Editora Nacional, 1987.

FLORENCE, Hercules. Viagem fluvial do Tietê ao Amazonas. São Paulo: Cultrix, 1977.

FONSECA, João Severiano da. Viagem ao redor do Brasil 1875-1878. Rio de Janeiro: Typographia de Pinheiro \& Cia, 1880.

GALLO, José Roberto. Fortificações de Mato Grosso do Sul. Secretaria de Desenvolvimento Social-Diretoria de Patrimônio Cultural, 1983.

MELLO, Raul Silveira de. Um homem do dever. Coronel Ricardo Franco de Almeida Serra. Rio de Janeiro: Biblioteca do Exército, 1964.

MOUTINHO, Joaquim Ferreira. Noticia sobre a província de Matto Grosso seguida d'um roterio da viagem de sua capital a São Paulo. São Paulo: Typographia de Henrique Schroeder, 1869.

PROENÇA, Augusto César. Pantanal, gente, tradição e história. Campo Grande: [s. n.], 1992.

SERRA, Ricardo Franco de Almeida. Extracto do Diário de diligência ao reconhecimento do rio Paraguay, desde o lugar do Marco, na boca do Jaurú, 1786. Revista do Instituto Histórico Geographico e Ethnographico Brasileiro, Rio de Janeiro: Kraus Reprint, v. 25, tomo XXV, 1973.

SIQUEIRA, Kiase Sebastiana Moraes. A inserção de estrangeiros nas sociedades fronteiriças: o caso dos paraguaios em Corumbá, MS. 2009. Dissertação (Mestrado em Estudos Fronteiriços) - Programa de Pós-Graduação em Estudos Fronteiriços, Universidade Federal de Mato Grosso do Sul, Corumbá, 2009.

SOUZA, João Batista de. Evolução histórica Sul de Mato Grosso. São Paulo: Organizações Simões, [s. d.]. 